\title{
Assessment of Contraceptive Uptake among Men Aged 20-50 Years in Mwembe Estate, Kisii Town, Kisii County, Kenya
}

\author{
Article by ${ }^{1}$ Taratisio Ndwiga, ${ }^{2}$ Angela Maiyo, ${ }^{3}$ Moraro R Bosire \\ ${ }^{1,3}$ Department of Environmental Health, Moi University, Kenya. ${ }^{1}$ School of Public \\ Health, Texila American University, ${ }^{2}$ Department of Emergency management studies, \\ Centre for disaster Management and Humanitarian Assistance Masinde Muliro \\ University, Kenya \\ Email: taratisiondwiga@yahoo.com,angela.maiyo@gmail.com, \\ morarorogers@gmail.com
}

\begin{abstract}
Background: Comprehensive contraception uptake involving not only women but also their male partners is very vital if the projected decline in fertility rates by 2025 is to be attained. Men's involvement is of great essence if potential acceptability of contraception programs is to be achieved.

Objective: The main objective of the study was to assess the utilization of contraceptives among men aged 20-50 years in Mwembe estate, Kisii Town.

Methodology: A cross-sectional study design was employed on 288 sampled men aged 2050 years. Stratified random sampling technique was used to select the respondents for the study. The data was collected using structured questionnaires and key informant guides.

Data Analysis: Analyses of quantitative data was done in SPSS version 20. Chi-square test was used to measure the strength of associations between the various variables where a pvalue of $=$ or $<0.05$ was considered statistically significant.

Findings: Condoms and vasectomy were the modern contraceptive methods available to men. 99\% of the study subjects had the knowledge on contraceptives but only $56 \%$ admitted consistent use. Among those who used, condoms were most preferred at 58\% with traditional methods still being employed. Only $32 \%$ of respondents had objections to contraception, among which $16 \%$ based on religious, $12 \%$ on personal and $4 \%$ on cultural reasons. The use of contraceptives was closely associated with religion $\left(\chi^{2}=6.67, d f=2, P V=0.036\right)$.

Discussion: The high awareness levels (99\%) can be attributed to technological advancements. Condoms use was leading (56\%) because they were easily available and accessible, they required no prescription and they offered dual protection. Vasectomy service utilization was low (1\%) as it had not been embraced in most societies. Religion was the major barrier of contraception (16\%) since contraception was thought to be against God's will. Other men (14\%) had personal reasons against contraception owing to the perceived side effects of female contraceptives in order to protect their women's health

Conclusion: Condoms were most common (70\%) than other methods hence information on proper use of condoms should be given. Knowledge on contraception was high (99\%) with low use (56\%) hence more is required to bridge the knowledge-practice gap. Utilization of contraceptives still low (56\%) compared to that of developing regions $(67 \%+)$. Religion, societal and personal holds hinder contraception practice.

Recommendations: Innovations of other contraceptive options through research by government. Men should be encouraged to take up contraception with communication among partners being emphasized. Health personnel to adopt religious-based and individual-based FP promotion approaches.
\end{abstract}

Keywords: Contraceptive, Utilization, Prevalence, Total Fertility Rate 
South American Journal of Public Health

Volume 4, Issue 1, 2016

\section{Introduction}

Globally, contraceptive prevalence among men forms a small subset of that (57\%) of women ${ }^{[1]}$. Contraception has played a great role in reducing fertility rates worldwide.

However, inadequate contraception strategies have continuously exacerbated the vulnerability of developing countries ${ }^{[2]}$.

Regionally, in most high fertility countries including those of sub-Saharan Africa, contraceptive use among married men has remained low [3]. The gap between knowledge on contraceptive use and actual use is still too large ${ }^{[4]}$. In addressing the dismal performance of many family planning programs, development practitioners and public health officials have directed great attention on contraceptive uptake among men ${ }^{[5]}$.

In Kenya, much focus on contraception has been directed on women, ignoring men who in most communities are perceived as main decision makers and who are equally involved in reproduction. Moreover, there exist very few recent studies on contraceptive uptake among men in Kenya. As a result, knowledge and attitude on contraceptive use among men is often shrouded in uncertainty ${ }^{[6]}$.

Contraceptive use among men in Kisii County is quite low. The only modern method used by men is the male condom $(0.8 \%)$. Traditional methods (rhythm \&withdrawal) are $3.4 \%$ prevalent. With the high population growth of $2.75 \%$, contraceptive prevalence of Kisii $(66.1 \%)$ needs to be increased to match or even be higher than that of Kirinyaga county (81\%), Kiambu county (74\%) and Meru county $(78 \%)$ with similar characteristic of high populations ${ }^{[7]}$. Men contraceptive uptake is a viable solution into achieving high contraceptive prevalence since men have an upper hand in family matters.

\section{Problem statement}

Total fertility rate (TFR) is one of the main indicators of socioeconomic development in any country in the world. Highly developed countries have TFR as low as 2 births per average woman ${ }^{[8]}$. This is unlike most developing countries that have TFR as high as 8 exacerbating the vulnerability of these countries, culminating into hard core poverty ${ }^{[6]}$.

Despite the reduction of TFR from 4.5 to 3.9 births per average woman, Kenyan population is still high and there is need for further reduction of TFR to ensure that resources are not depleted. Kenya's population growth is about one million people annually. With this high population, resources have continuously been depleted, frequent food shortages experienced, with diseases and malnutrition prevailing.

With the recent shift of contraception programs from being focused on women only to focusing on men individually, or on both partners, great emphasis on men's full participation is required ${ }^{[3]}$. There exists limited choice of men's contraception options as compared to the wide variety available for women contraception services in most parts of the country ${ }^{[1]}$. Even with the existing options, male contraceptive use still remains low.

Kisii is one the counties contributing to the high fertility rate in the country, with quite a high alarming annual growth rate of $2.75 \%{ }^{[9]}$. Kisii District has a total fertility rate higher than the national average ${ }^{[10 \mathrm{a}]}$. Kisii District reported one of the highest fertility rates in the world, as per a Kenyan Conundrum Regional analysis. With these high population, scarcity of resources especially land have over time been experienced. In 2009, Contraceptive acceptance in the former Kisii Central District was rated at $35 \%{ }^{[10 b]}$.

Mwembe is part of the most densely populated location; Nyaura location (with 4818 people per sq.km) in Kisii Township. Going by 2009 KNBS census report, 57\% of inhabitants in Mwembe are below the age of 15 years depicting high dependency 
ratios. With the high population especially children and youth, there existed insufficient distribution of modern contraceptives. There was also hardly no ongoing contraception promotion programs among the people. The low contraceptive acceptance of $35 \%{ }^{[10 \mathrm{~b}]}$ has greatly contributed to low living standards in the area.

Men's role in reproductive health remains an integral yet neglected part of understanding fertility control. The male partner's fertility desires more often influence even women's contraceptive use ${ }^{[11]}$. The lack of male involvement places the heavy burden of reproductive health decision-making solely on the woman. The International Conference on Population and Development (ICPD) Program of Action emphasized that the active participation of both men and women is essential for reducing unmet need for contraception. Knowledge about contraception among men has been high, as high as $90 \%$ but attitude has not been positive and practice has been low. This exemplifies existent knowledge - attitude - practice gap in contraceptive use ${ }^{[12]}$. Men's involvement in contraception and policies is necessary to increase contraceptive uptake and reduce fertility rates. The study sought to determine whether men are taking up contraceptives to boost on contraceptive prevalence most often accounted on women.

\section{Study justification}

The study has environmental, societal and economic significance. By reducing total fertility rates (TFR), better utilization and distribution of resources will be achieved thus improving on people's quality of life. Government planning will also ease with controlled fertility rates.

This study is also significant to public health since by lowering fertility rates, population growth and its effects will also decline. Effects like disease due to overcrowding will be curbed. Macronutrient deficiencies and disease especially among children due to large numbers of children and low family income will also be reduced.

The studies aim at filling a gap in knowledge on contraceptive uptake among men and create baseline data viable for further research. It is hoped that the findings of the study will inform policy makers on contraceptive uptake among men and will contribute to the growing need for gender transformative programs in $\mathrm{MCH} / \mathrm{FP}$.

The broad objective of this study was to assess the utilization of contraceptives uptake among men aged 20-50 years in Mwembe estate, Kisii Town.

\section{Literature review}

\section{Contraception}

Contraception, also birth control is a practice in which individuals and couples use methods, devices or surgery to prevent pregnancy ${ }^{[13]}$. Male contraception methods vary from most effective method which is sterilization (vasectomy) to less effective, that is condoms. There also exist least effective options like withdrawal and periodic abstinence. Vasectomy is usually irreversible whereas all the other methods are reversible ${ }^{[14]}$.

Planning, provision and use of contraceptives is known as family planning ${ }^{15]}$. If effectively embraced, family planning has a positive impact on health of the parents and on the child ${ }^{16]}$.

\section{Benefits of contraception}

Ensuring access to a wide variety of contraceptive methods for couples is very vital in supporting health of families and communities' development at large. Effective contraception uptake helps in controlling rapid population growth. Unsustainable population growth rates are slowed down to match the available resources. This helps 
achieve environmental sustainability and economic growth both regionally and nationally ${ }^{[17]}$.

Contraception prevents health risks related to pregnancy among reproductive women. Women's health and wellbeing is greatly impacted when they are able to choose if and when to become expectant. Maternal mortality risks normally experienced among women giving birth at very old age or very early childbearing are reduced. With family planning, a couple is able to decide and have families of their desired size ${ }^{[18]}$.

Adolescent pregnancies are reduced through contraception. Contraceptive-uptake greatly lessens the eventualities of young girl' pregnancies which in many times end up as preterm or low birth-weight babies. High neonatal mortality rates linked to babies born to adolescents are also greatly reduced, same to incidences of school drop outs ${ }^{[16]}$. Contraceptive uptake has an impact on infant mortality rates. Infants deaths experienced due to closely-spaced and unplanned pregnancies (cause of highest infant mortality rates in the world), are significantly prevented through contraception ${ }^{[18]}$.

HIV/AIDS is also prevented more so by use of condoms which provide dual protection; against unintended pregnancies and contracting HIV/AIDS. Contraception, if embraced among infected individuals and couples would reduce unintended pregnancies, some of which result in HIV infected babies, who eventually remain orphaned ${ }^{[19]}$. In a broader context, planning and use of contraceptives empowers society. Couples are given a platform to make informed decisions on their sexual and reproductive health. Based on individual's abilities and resources, education imparted enhances making of wise choices on family sizes ${ }^{[16]}$.

\section{Provision of contraception}

Contraception should be made widely available and accessible to every sexually active individual. The initial levels of health care service provision should be improved. Proper training on provision of locally available and culturally accepted contraceptive options should be given to midwives and Community Health Workers. Individuals and the communities should be counseled and educated on contraception. For more sophisticated methods e.g. sterilization, people should be referred to clinicians in the nearest health facilities ${ }^{[1]}$.

\section{Modern methods}

Male condoms and vasectomy are the only modern contraceptive methods so far developed limiting choice and user preference ${ }^{[1]}$. Male condoms are thin rubber sheaths worn on men's erect penises as a covering during sexual intercourse. They are designed to form a barrier to intercept sperms from meeting the egg. If correctly and consistently used, they offer $98 \%$ effectiveness in preventing pregnancy. In addition to use as a contraceptive, they protect against sexually transmitted diseases, HIV infections included ${ }^{[20]}$.

Vasectomy is a reliable contraception involving surgical procedure carried out on males where each part of the vas deferens is cut and sealed, to achieve sterilization. The flow of sperms from the testicles is cut off, keeping them out of the ejaculated semen. It is above $99 \%$ effective after sperm evaluation for a three month period. Moreover, vasectomy does not affect male sexual performance and has a lower failure rate than sterilization in women ${ }^{[21]}$.

\section{Traditional methods}

Withdrawal (Coitus interruptus) is aimed at preventing fertilization in that, upon ejaculation during sexual intercourse, a man draws out the penis and ejaculates outside the woman's vagina and external genitalia. It offers $96 \%$ effectiveness in preventing pregnancy when correctly and consistently used. Many couples use it 
because of convenience, although, its effectiveness is somehow compromised, owing to the fact that proper timing of withdrawal is difficult ${ }^{[22]}$.

Periodic abstinence (the rhythm or calendar method) refers to avoiding unprotected vaginal sex during the woman's most fertility days. Achieved through calendar-based methods; monitoring fertile days in the cycle of menstruation, cervical mucus and body temperature monitoring. If correctly and consistently used, they form $95-97 \%$ effectiveness in preventing pregnancy, though it requires maximum cooperation among sexual partners ${ }^{[23]}$.

\section{Contraceptive utilization among men}

Contraceptive use has for the recent past remained to be low in sub - Saharan Africa unlike Asia and Latin America where it has been on the rise ${ }^{[1]}$. A slight increase in modern contraception has been recorded globally, that is, from $54 \%$ in 1990 to $57 \%$ in 2012, although there exists great unmet need for men contraceptives.

Condom use is high in sub - Saharan Africa hence indicating a higher preference of condom to vasectomy ${ }^{[24]}$. In a study conducted in Ekpoma, Nigeria, the most common contraceptive choice $(85.9 \%)$ among men was the use of condoms ${ }^{[25]}$. The unwillingness among men towards condom use can be attributed to reduction of enjoyment during sexual intercourse. Moreover, men tend to be inconsistent and irregular in the use of condoms ${ }^{[26]}$. This in most cases results in unwanted pregnancies among their women, which makes the women not to prefer methods like condom use that rely on their partner's willingness.

In developing countries, male sterilization (vasectomy) is not common and even never adopted at all in some. This is unlike in developed countries including China, India, Korea, etc. where it is widely practiced. The notion that vasectomy renders one permanently sterile with minimal or no chances of reversing the procedure makes it unpopular among men in developing countries ${ }^{[27]}$. Though seldom practiced, women prefer sterilization option as a method of contraception among their male sexual partners to condom use ${ }^{[28]}$.

Condoms and vasectomy being the only modern methods of contraception, there exists a great unmet need of contraceptive methods for men ${ }^{[29]}$. Access to contraception among adolescents is notably heavily dependent on publicly funded family planning services ${ }^{[30]}$. Owing to these facts, government has a part to play of offering contraception in order to attain population control for economic development.

In a survey conducted among inhabitants of Czech, withdrawal was most preferred $(38 \%)$, with natural methods at $12 \%$ after condoms $(22 \%)$. Although men prefer withdrawal as a method of contraception, traditional contraception methods are associated with high abortion rates as compared to modern contraceptive methods ${ }^{[31]}$. This raises a question of ineffectiveness or inconsistently with traditional contraceptive methods. However, most men prefer traditional methods (safe-period methods) because they want to protect their women's health resulting in low modern contraceptive uptake ${ }^{[11]}$.

\section{Barriers to contraceptive uptake among men}

The major barriers preventing uptake of contraceptive services include cultural, religious, social and economic barriers ${ }^{[32]}$.

Cultural traditions strongly influence birth rates in some regions. Marriage at young ages and the virtual absence of contraceptive use eventually results to high population growth rates. In Bangladesh for instance, the norm is that women at married at age 16 or 17 and at average, a woman becomes pregnant nine times. A very low percent $(16 \%)$ in Bangladesh use contraception, which in most cases are traditional, forms that is, withdrawal and periodic abstinence. An interesting fact in developing 
countries is that most women do not want many children, but yet still the women and even their spouses in some cases do not want to use contraceptives ${ }^{[33]}$. Nevertheless, adoption of contraception programs would greatly reduce the high fertility rates in underdeveloped countries.

Culture is not homogenous especially in regions with many dialects. Traditional African societies share common beliefs, cultural values, customs and traditions especially regarding fertility behavior and related areas. Religious beliefs in a Supreme Being and several lesser gods or deities and practices including ancestral worship are the most common characteristic, associated with the religious system are beliefs about reproduction and pro-natalist practices. The general concept about life is that there is life after death and that the dead are in touch with the living and blesses them with the offspring. Infertility is a curse and a sign of the displeasure of the ancestors, while the children are viewed as wealth in Africa. The value of children is high and derives from the economic value of children as family labor and as valuable security against old age. Until recently, it has been considered prestigious to have many wives and children, with the wealth of a man measured in terms of his family size, while the woman was honored when she bore many children, but was stigmatized if she could not bear children. There are many African proverbs that buttress the importance of children and large family size like "Even ghosts have to increase in number" - Akan, Ghana and "A woman whose sons have died is richer than a barren woman" of the Kikuyu, Kenya ${ }^{[13]}$.

Religious attitudes and beliefs are also potential barriers to the effectiveness of contraception programs. From the bible (King James Version), in Genesis 1:27, 28, it reads, "So God created man in his own image, in the image of God created he him, male and female created he them. And God blessed them, and God said unto them, Be faithful, and multiply, and replenish the earth, and subdue it, and have dominion over the fish of the sea, and over the fowl of the air, and over living thing that moveth upon the earth." The Roman Catholic Church is strongly opposed to contraceptive use apart from natural methods like abstinence, and holds them as sin. Religious beliefs therefore have influence on contraceptive usage among billions of religious followers and family size in many countries especially in Latin America or the Middle East ${ }^{[34]}$.

Many societies hold onto the attitude that having many children is good. People want large families for economic security. Having many children is advantageous as held by many, since they provide enough labor in farm work and other duties. Parents also foresee situations of getting old and wanting to have children to take care of them, eliciting the need for many children. In addition, parents want to bare many children taking into account the fact that some of the children may die, perhaps in circumstances like disease and malnutrition. Socioeconomic aspects therefore form barriers to contraceptive uptake ${ }^{[33]}$.

For success in contraceptive use among populations of sub-Saharan Africa, a strategy encompassing cultural and societal norms for the target populations is key due to the diversity of populations involved ${ }^{[35]}$.

\section{Methodology}

\section{Study area and period}

The study was conducted in the Southwestern part of Kenya, Kisii County, Mwembe Estate (figure 1) within Kisii Township from $1^{\text {st }}$ October $-30^{\text {th }}$ November, 2015. Kisii is the capital Town of Kisii County. Kisii County is one of the 47 counties of Kenya bordered by six countries namely; Nyamira county to the east, Migori county to the west, Homabay county to the northwest, Kisumu county to the north, Bomet to the southeast and Narok county to the south. It is inhabited by the Gusii people and forms one of the most densely populated areas in the country. The total 
population of Kisii, as per Kenya National Census Report of 2009 is 1,152,282 with 553,095 men, forming up $48 \%$ of the population ${ }^{[9]}$.

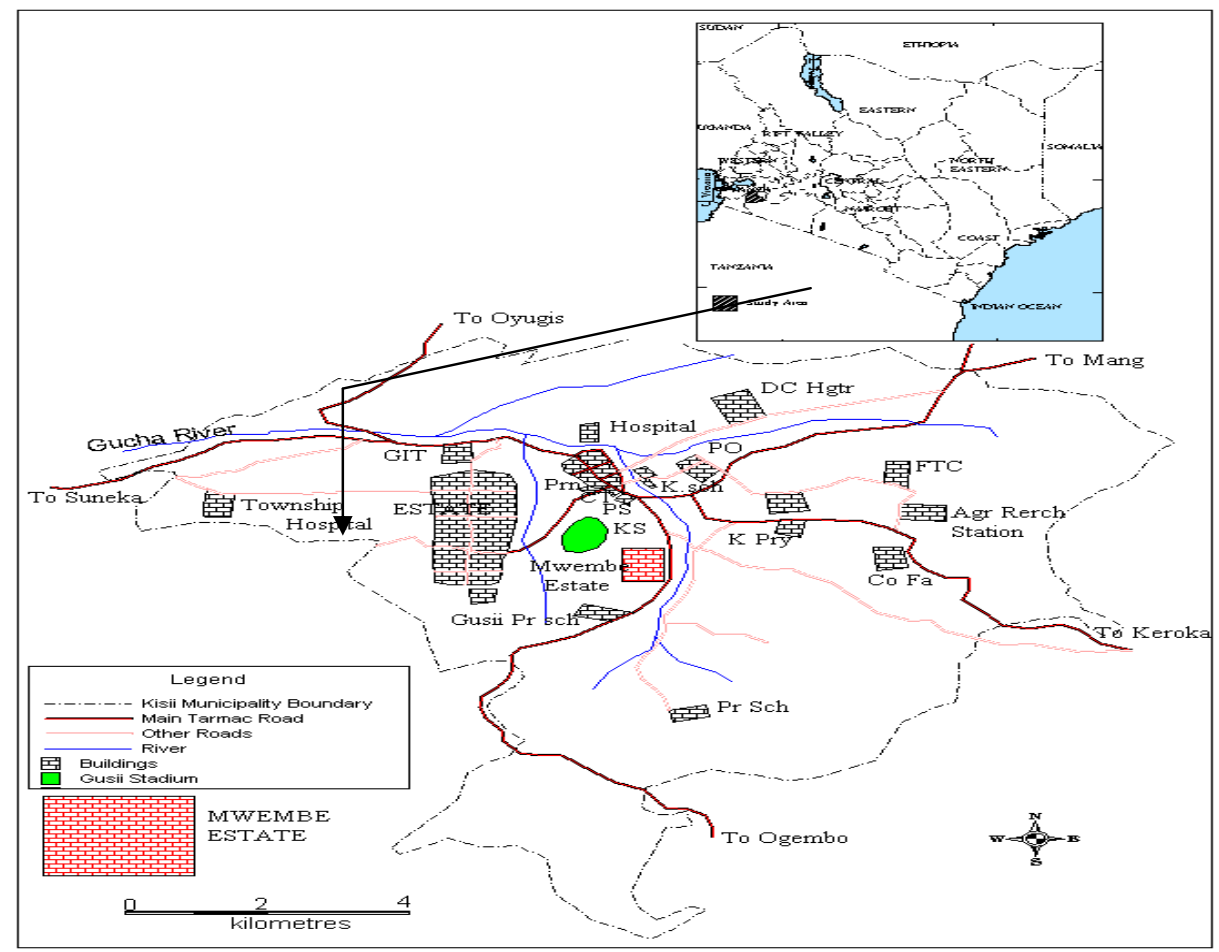

Figure 1. The map of kisii town showing mwembe estate

Mwembe estate, one of the most densely populated suburbs, is a residential cum business area within Kisii Township. It has a total population of 8137 people comprising of 4032 males and 4105 females. The population growth trends as per KNBS 2014, Kisii office records show an alarming increase in the number of inhabitants year after year. Going by the age distribution of the area, there are a total of 1152 men between ages 20 and 50 years ${ }^{[7]}$.

\section{Target, study population and study design}

The target population were all men in households who in the $20-50$ years age bracket who resided in Mwembe, Kisii Township. Men between ages 20 and 50 years are the most sexually active age group with those in 15-19 years age bracket being considered as teens and school going. The study population sampled men who were within ages $20-50$ years in Mwembe, Kisii Township. The cross-sectional study design was adopted and souht to assess the uptake of contraception among men aged 20 - 50 years. Mwembe estate in Nyaura Location was purposively selected due to its high fertility rate and population growth characteristic. The sample size was calculated using the ${ }^{[36]}$ formula, considering a confidence interval of $5 \%$ which gives the final sample size as 288 respondents. The area was clustered into three enumeration areas; Mwembe upper, Milimani 1 and Milimani 2, with 478, 308, 366 men (aged 20-50 years) respectively. The enumeration areas were demarcated by roads easing the sampling and data collection procedure. Well representation of each cluster was ensured by selecting participants in the proportion of their populations; $(478 / 4)=119$ from Mwembe Upper, $(308 / 4)=77$ from Milimani I, and $(366 / 4)=92$ from Milimani II.

Stratified random sampling was carried out to pick the study subjects from every enumeration area at every $4^{\text {th }}$ interval. The interval was arrived at, by dividing each enumeration area's male population (those between age 20 and 50 years) by the sample size required of that area. The first household of each area at a common 
intersection point formed the starting point of data collection in each area, proceeding at every $4^{\text {th }}$ interval. If there was respondent in the household, the next household was visited until the desired sample size was attained.

Inclusive criteria were all the men who are within the sexually active age (20-50 years) and who gave consent and willing to participate in the study. Men below 15-19 years though sexually active were excluded from the study since they are school going.

\section{Data and data collection tools}

Both qualitative and quantitative data was collected during the study using structured questionnaires and interview guides.

The questionnaires consisted of three parts. The first part contained demographic questions, the second part contained the known and preferred men contraceptive methods and the last consisted of questions relating to barriers to contraceptive uptake. The required data was collected by the researcher through face to face interviews. Prior to the start of data collection, the purpose of conducting the study was explained to the participants for them to express their willingness by granting consent.

Interview Guides was also used to obtain information from two nurses in the family planning clinic in Kisii Level 5 Hospital; the head nurse and the one on duty. Information on contraception services offered and on family planning seeking behavior among men was also obtained.

\section{Data collection procedures and data processing and analysis}

Questionnaires were administered by the researcher on the sampled men according to the stated sampling criteria, interview guides were used to obtain information from the family planning in-charge and one of the family planning nurses. All the questionnaires were used during data collection period. After data collection was completed, data entry, cleaning and analysis was done by using the Statistical Package for Social Sciences (SPSS) software, version 20 Program.

In order to describe the descriptive statistic, frequencies and percentages were computed and represented in bar graphs, pie charts and tables. Qualitative data was analyzed in relation to the study variables. Chi-square test was used to measure the strength of associations between the various variables where a $\mathrm{p}$-value of $=$ or $<0.05$ was considered statistically significant. As the Value of Muslims who did not practice contraception was zero (less than 5), Yates correction was applied to the chi-square data.

\section{Ethical consideration and plan for data collection}

Ethical clearance was sought from Institutional research and ethics committee (IREC) from Moi University and the school of Public health, Texila American University, Kisii County Public Health Office and from the area chief. Written consent was sought from the study subject after being provided adequate information by reading the information sheet that described the purpose of the study and its confidentiality and beneficence.

Three first year Public health students from Moi University, College of Health Sciences were recruited as research assistants. Prior to the actual fieldwork, research assistants were trained and participated in pre-testing the questionnaire. Pre-testing of the study instruments was done a week before execution of the study to men aged 2050 years in Langas estate, Uasin-Gishu County. 


\section{Results and findings}

\section{Contraceptive options available for men}

According to the Kisii Referral and Training Hospital Family Planning Department, the modern contraceptive options that were available for men were mainly condoms. From the interview guide, at least 45 men sought contraceptive services on monthly basis. Those who sought condom services were almost $100 \%$ compared to other services. Vasectomy services were available but had hardly been carried out in the hospital.

Only three condom dispensing boxes were observed in the hospital which were refilled once every week as revealed by the head of the hospital family planning department. Each dispensing box carried about 50 dozens of condoms. The dispensing boxes mostly benefited the hospital staff and patients. However, men who do not get condoms from the hospital dispensing boxes but instead obtain them from private dispensing units in chemists, supermarkets, etc.

\section{Socio-Demographics}

All the respondents $(n=288)$ were male, with majority of them $(48 \% n=138)$ being in the $20-30$ age bracket while 31-40 amounted to $32 \%$. Those between 40 and 50 years formed $20 \%(n=58)$, the least percentage. Single men formed $26 \%(n=75)$ with $74 \%(n=213)$ being married. No divorced or widowed men participated in the study. The education levels of the respondents were categorized into primary, secondary and tertiary levels. Majority $(42 \%, \mathrm{n}=121)$ of the respondents had attained secondary education, while college/University scored $32 \%,(n=92)$. The primary level scored the least percentage at $26 \%,(n=75)$.

Protestants formed the largest percentage $(64 \%, n=184)$ of the religions represented in Mwembe estate with Catholic following at 34\% (n=98) and Muslims at $2 \%(n=6)$ as shown in figure 2 below.

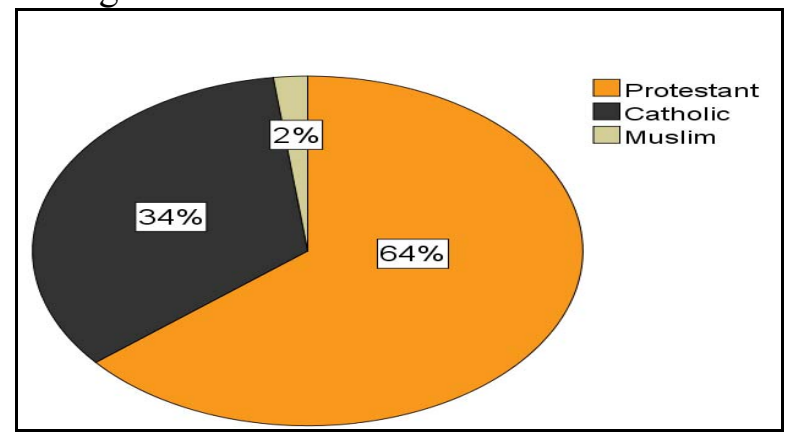

Figure 2. Representation of religious affiliations

\section{Knowledge on contraception among men}

Ninety nine percent $(99 \%, \mathrm{n}=285)$ of the study subjects had the knowledge on contraceptives while the $1 \%, n=3$ had no knowledge of the same. Out of the 285 men, use of condoms accounted for $91 \%,(n=262)$, the most popular among men with male sterilization (vasectomy) being the least popular at $2 \%,(n=6)$, see table 1 . Out of the 288 respondents, 109 of them (38\%) heard contraception issues from the radio, 15\% had seen in television with the least source of information being friend talks at $9 \%$ $(n=26)$. 
South American Journal of Public Health

Volume 4, Issue 1, 2016

Table 1. The various contraceptive options among men

\begin{tabular}{|l|l|l|}
\hline $\begin{array}{l}\text { Contraceptive } \\
\text { Option }\end{array}$ & Number & Percentage (\%) \\
\hline Condom & 262 & 91 \\
\hline Vasectomy & 6 & 2 \\
\hline Withdrawal & 12 & 4 \\
\hline $\begin{array}{l}\text { Periodic Abstinence } \\
\text { from sex }\end{array}$ & 8 & 3 \\
\hline Totals & 288 & \\
\hline
\end{tabular}

Uptake of contraceptives among men

On contraceptive use, $56 \%(n=161)$ admitted consistent use of male contraceptives. Those who did not use contraceptives formed $44 \%(n=127)$ as shown below.

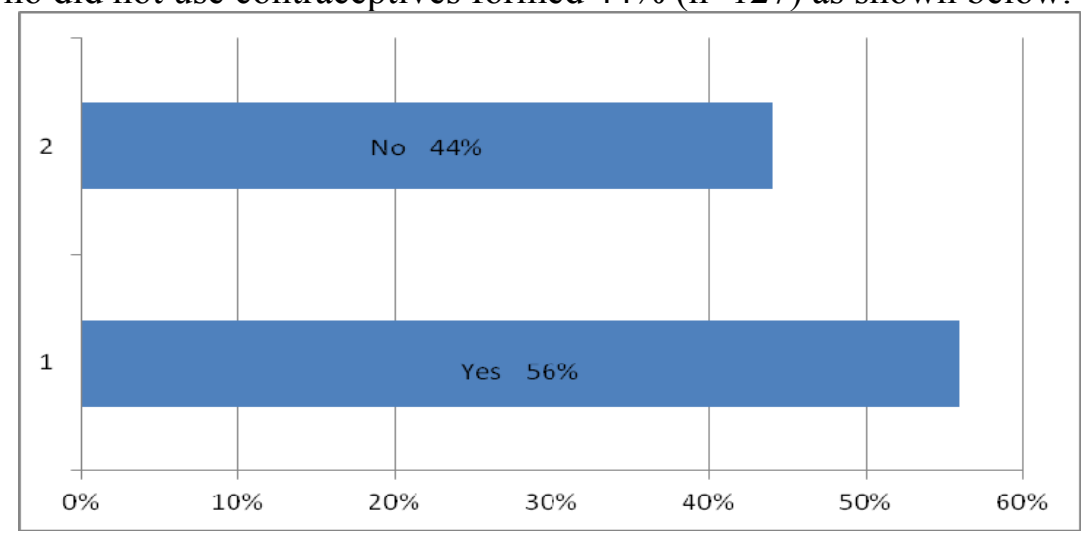

Figure 3. Use of contraceptives by men

The contraceptive methods employed by the $56 \%(n=161)$ above who admitted consistent use are represented in the Figure 4 below.

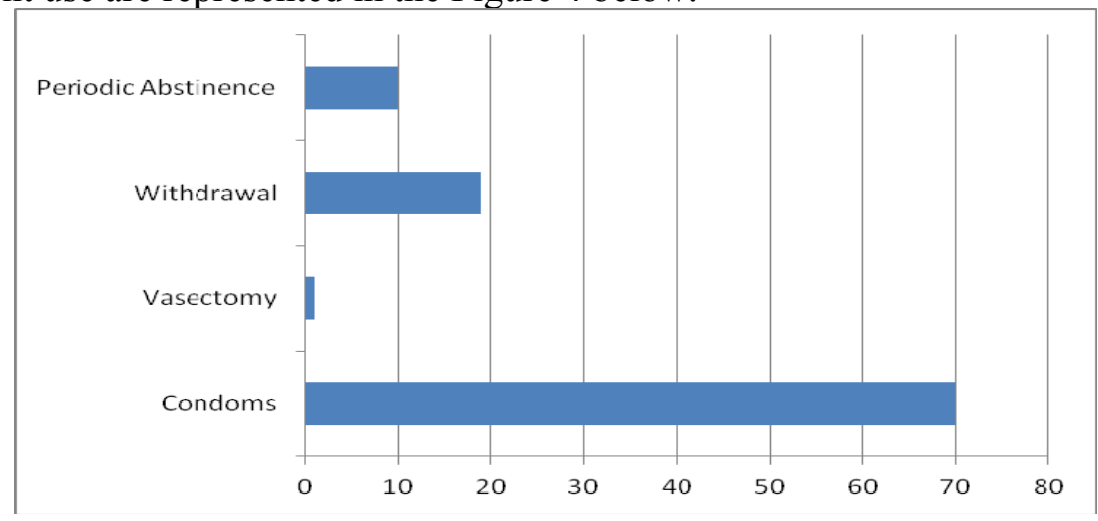

Figure 4. Contraceptive methods used by men

The use of contraceptives was closely associated with religion $\left(\chi^{2}=38.49^{\prime} \mathrm{df}=2\right.$, $\mathrm{P}$ $=0.036)$. The men of different religious faiths who and who did not practice contraceptive followed the downward trend, i.e. Protestants, Catholics and Muslims. The odd ratio results calculated suggested that Protestants were 5 times more likely to use Contraceptives than the Catholics.

Barriers to contraceptives utilization among men

The representations of the study subjects' objection on contraceptive use is shown in figure 5 below. 


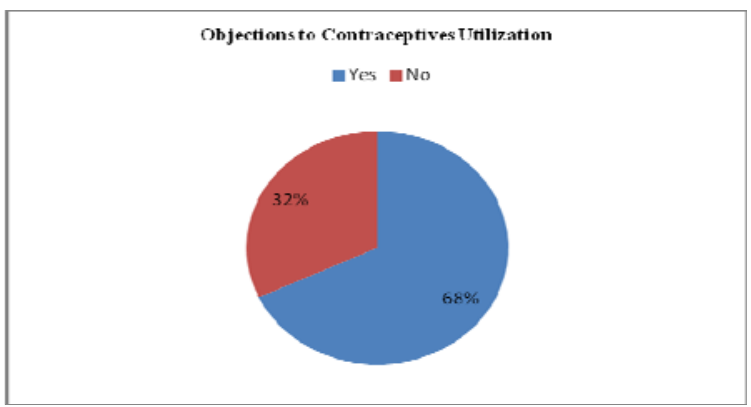

Figure 5. Objections to contraceptives utilization

The specific objections given on contraceptive use were based on religious, personal and cultural reasons. Those who had followed religion were $16 \%(n=46)$, Cultural $4 \%(n=12)$, personal $12 \%(n=35)$ and none $68 \%(n=196)$. The religious barriers to contraceptive were 4 times higher compared to the cultural, one and a quarter times more than the personal barriers. Those who reported no barriers accounted for $68 \%$.

\section{Discussion}

\section{Contraceptive options available for men}

The modern contraceptives available were condoms and vasectomy but condoms were mostly (70\%) used. This was because condoms were easily obtained, easy to use as no prescriptions are required. On the other hand they offer dual protection that is against STIs and unwanted pregnancies at the same time. Moreover condoms allow men to share the responsibility for prevention of pregnancy and protection against STIs ${ }^{[19]}$.

Vasectomy preference and use (2\%) was low since it had not yet been embraced by most societies due to the fear of its irreversibility aspect by many. Most men find it odd to go for sterilization after achieving the desired number of children to prevent more births. This is unlike in a study by ${ }^{[37]}$ conducted in Nepal where vasectomy was high at $12 \%$ after female sterilization (30\%). Men in developed countries including Korea and China have also embraced vasectomy as a birth control method ${ }^{[27]}$. In these countries, commendable fertility rates as low as one child per family have been achieved, a direction that developing regions should take ${ }^{[38]}$.

\section{Knowledge on male contraception}

The large proportion (99\%) of men had heard and knew about contraception. This agrees with a study by ${ }^{[39]}$ conducted in Ethiopia where all $(100 \%)$ the respondents had heard of contraception. The study further stated that individuals who have adequate information about the available methods of contraception are able to make choices about planning their families ${ }^{[39]}$. Also, according to the KNBS, 2010, $98 \%$ of men were aware of contraception, a statistic slightly lower than the finding of this study.

The main source of information on contraception was media; radio (38\%) and television (15\%), a statistic similar to other studies. A study among Greek women and men also reported media as the primary source of contraceptive information ${ }^{[40]}$. This can be attributed to the recent technological advances where every household has at least one media device ${ }^{[41]}$. Exposure of family planning messages through media plays an important role in increasing the use of family planning methods especially in areas where illiteracy levels are high.

The most widely known modern methods of contraception among men was the condom $(91 \%)$, with vasectomy at a low $2 \%$. With regard to traditional methods, $4 \%$ had heard of withdrawal and 3\% about periodic abstinence. This is in line with a survey where condoms were most known among men at $96.1 \%{ }^{[10 \mathrm{a}]}$, but disagrees 
with periodic abstinence (rhythm method) and withdrawal at 69.5 and 63.4 respectively [10a] against the found results at Mwembe estate at $4 \%$ and $5 \%$ respectively. Similarly in a study in Pakistan, condom was the most known method $(27.3 \%)$ followed by withdrawal and periodic abstinence ${ }^{[42]}$. Vasectomy in Mwembe estate was very low (2\%), compared to $58.1 \%{ }^{[10 \mathrm{a}]}$ in Kenya.

\section{Uptake of contraceptives among men}

Slightly above half of the men $(56 \%)$ admitted use of at least one male contraceptive method. As with previous studies the contraceptive method employed by most men was the condom, followed by traditional methods with some employing more than one ${ }^{[25],[43],[42]}$. Vasectomy however was employed by a negligible proportion of $2 \%$. Of the $56 \%$ who admitted consistent use, $38 \%$ used condoms, $4 \%$ withdrawal, $3 \%$ periodic abstinence and only $2 \%$ used vasectomy. This concurs with a study done in Ekpoma, Nigeria where condoms were the most prevalent contraceptive choice $(85.9 \%)$ among men $^{[25]}$. The findings are also similar to contraceptive prevalence in a study in Accra, Ghana where methods requiring male participation (condoms, traditional methods or a combination of the two) were the most prevalent ${ }^{[43]}$. It is also in consonance with a study conducted in Pakistan where condoms were mostly used $(27.3 \%)$ and traditional methods used by $6.7 \%$ with vasectomy at zero ${ }^{[42]}$. Condoms were easily obtained and easily to use though cumbersome especially among married men ${ }^{[25]}$. Traditional methods were perhaps still being employed among men due to the existing limited choice of male contraceptive options.

Uptake of contraception was closely related to religion with a statistical significance of $P=0.036$. Majority of Catholics $22 \%(n=63)$ out of the $29 \%(n=83)$ catholic respondents did not use contraceptives. Protestants were 5 times more likely to use Contraceptives than the Catholics. Out of the $69 \%(n=199)$ Protestant respondents, $42 \%(n=121)$ admitted use whereas $22 \%(n=78)$ did not. All the Muslims (2\%) did not use contraceptives. This agrees with a study done in Kenya that affirms the fact that religious affiliations are a significant predictor of contraceptive use. The study further revealed that $51 \%$ of Muslims are more likely not to adopt contraception, with adoption of contraception among Protestants and Catholics being more or less similar ${ }^{[44]}$.

\section{Barriers to contraceptive uptake among men (users)}

A larger percentage $(68 \%, n=196)$ of men respondents were not opposed to contraception perhaps due to its benefits; attaining desired family size and preventing spread of STIs. Among those opposed $16 \%(\mathrm{n}=46)$ gave religious reasons. Contraception was perceived to enhance adultery thus separating sex from reproduction. This, they said was "against God's will" of reproduction. This agrees with a Kenyan study in which contraception was associated with promiscuity and straying, a notion that formed a major barrier to contraceptive use ${ }^{[45]}$.

Contraception as was held by other men, prevented births of people who might benefit the humanity from occurring and potential human beings from being born. It was described as a contributive factor to or a form of abortion since the sperms released do not reach and do the function of reproduction. Life being a fundamental right, contraceptive use was held as an anti-life. Those who use contraceptives were perceived to be engaging in an intentionally 'anti-life' act because they tend to prevent a new life from coming into being ${ }^{[46]}$.

Of the $32 \%(n=92$ out of 288 respondents $), 12 \%(n=35)$ had personal reasons barring them from adopting contraception whereas $4 \%(n=12)$ were barred by culture. The personal and cultural reasons given were however closely related. Most respondents, who gave personal reasons, mentioned real side effects, especially those 
of female contraception option. The most common side effects expressed by the respondents were lack of sexual desire. Female partner' loss of weight and bleeding were also cited by a few. This was a similar statistic to a study conducted in former Nyanza Province, Kenya where side effects were a main concern, specifically bleeding of women towards men contraception uptake ${ }^{[47]}$. Condoms were reported to be cumbersome and most married men did not prefer using them because they were married. This is in line with a study where condom use was associated to unfaithfulness ${ }^{[48]}$. Cultural barriers as explained by the $4 \%$ of men opposed to contraceptive use varied from "children are a blessing from God/gods" to "children being wealth" and "security during old age." However evident from the findings, the $4 \%(n=13)$ opposed to contraception, cultural barriers had greatly faded away. This was so perhaps because of the high cost of living in urban settings ${ }^{[49]}$. Cultural practices in urban settings demands a lot more of expenditures than in rural areas.

\section{Conclusions}

\section{Introduction}

Advocating for contraceptive uptake among men is not only key in curbing high fertility rates but also in preventing HIV/AIDS control. In addition it will contribute to reduced infant and maternal deaths through control of unwanted pregnancies. If effectively embraced, contraception will have a positive impact on health of the parents and on the child.

\section{Contraceptive options available for men}

The male condom was the most readily available male contraceptive option in Kisii Level 6 Hospital in condom dispensers. They were also available for sale in drug dispensing units in supermarkets, chemists' etc. Vasectomy services were offered but were unpopular among men.

The limited choice of contraceptive option among men prompted the use of traditional methods like withdrawal and periodic abstinence despite them being least effective alternative of birth control

\section{Knowledge on contraceptive use}

Conclusively, the most common disseminator for contraception information was media; radio (38\%) and television (15\%). Health facilities also had great potential in disseminating information on contraception (14\%). In order to achieve high contraceptive prevalence rates, proper information on contraceptive use, highlighting its advantages should be propagated more often on media; television, newspapers, journals and more so on radio. Health facilities should also best avenues for disseminating information on contraceptive use.

\section{Contraceptive use among men}

The mostly used male contraceptives were the condom (70\%). In order to control rapid population growth and curb sexually transmitted diseases, correct information on condom use should be disseminated among men. However uptake of vasectomy services should be encouraged in health facilities more so among men, who've finished child bearing.

Traditional contraceptive methods' use was still employed (withdrawal, 19\% and periodic abstinence, 10\%) among men despite being least effective. However used, unwanted pregnancies were not effectively controlled thus encouraging abortions. This calls on research to give alternative effective and acceptable methods for this large number of men still employing traditional contraception. 
South American Journal of Public Health

Volume 4, Issue 1, 2016

\section{Barriers of contraceptive uptake among men}

There existed potential barriers hindering its full acceptability in societies with religious (16\%) and personal reason barriers (12\%) are high. This calls on religiousbased and individual-based approaches to raising contraceptive acceptance. By addressing personal reasons, most of the cultural holds against contraceptive use will be neutralized because the two went hand in hand.

\section{Recommendations}

- Contraceptives should be made more readily available and sufficient especially to men in peri-urban and rural areas at no or low cost by the county government health authorities.

- Educational and promotional programs and campaigns should be frequently organized in form of road-shows, public meetings among others to help give meaning to contraception especially among those opposed to contraceptive use.

- Health personnel should adopt religious-based and individual-based FP promotion approaches in order to encourage contraceptive uptake.

- Communication among partners should be encouraged through efficient channels of communication like radio and TV so as to increase partner support in using contraceptives to space or limit childbearing.

\section{References}

[1]. Abdulla, S. (2014) Religious Affiliation and Contraceptive Use in Kenya. University of Witwatersrand. Johannesburg. Pg 65.

[2]. Atieno, P. O. (2010) "Men's knowledge, attitude and practise of family planning in Kenya." Digital Repository: University of Nairobi.

[3]. Berhane, A., Biadgilign, S., Amberbir, A., Morankar, S., Berhane, A., \& Deribe, K. (2011). Men's knowledge and spousal communication about modern family planning methods in Ethiopia. African journal of reproductive health, 15(4), 24-32.

[4]. Briggs, P and Kovacs, G. (2013) Contraception: A Casebook from Menarche to Menopause. Cambridge: Cambridge University Press.

[5]. Callahan, T and Caughey, A. B. (2013) Blueprints Obstetrics and Gynecology. Baltimore: Lippincott Williams \& Wilkins.

[6]. Carroll, J. (2015) Sexuality Now: Embracing Diversity. Boston: Cengage Learning.

[7]. Castaneda, D. M. (2013) The Essential Handbook of Women Sexuality [2 Volumes]. Santa Barbara: ABC CLIO.

[8]. Cunha, C and Manuela. M. (2009) Handbook of Research on Developments in E-Health and Telemedicine: Technological and Social Perspectives. New York: Medical Information Science Reference.

[9]. Dahal, G.P., Sabu, S., Padmadas, R and Hinde, A. (2008) Fertility-Limitng Behaviour and Contraceptive Choice among Men in Nepal. International Family Planning Perspectives: Guttmacher institute. pages 23.

[10]. Edberg, M. (2010) Essential Readings in Health Behaviour: Theory and Practise. Sodbury: Jones \& Barlett Publishers.

[11]. Eldra, S., Martin, C and Martin, D. (2014) Biology. New York: Cengage Learning.

[12]. Fisher, A. A., Laing, J. E. and Strocker, J.E. (1998) Handbook for Family Planning, Operation Research Design in Sampling. Population Council, 40-45.

[13]. Fogel, C.I and Woods, N. F. (2008) Women's Health Care in Advanced Practise Nursing. New York: Springer Publing Company.

[14]. Haider, T.L and Sharma, M. (2013) Barriers to Family Planning and Contraception Uptake in sub - Saharan Africa: A Systematic Review. Bethesda: PubMed Publisher.

[15]. Handler A and Kennelly. J (2010) Reducing Racial/Ethnic Disparities in Reproductive and Perinatal Outcomes. Chicago: Springer Science \& Business Media.

[16]. Hanson S. J and Burke A E (2011) Fertility Control: Contraception, sterilization and abortion: In K.J Hurt; M. W guile; J. L Bienstock. The John Hopkins Manual of gynecology and obstetrics, $4^{\text {th }}$ edition. 
[17]. Imhoff, D and Baumgartner, J. A. (2012) Farming and the Fate of Wild Nature: Essays in Conservationbased Agriculture. Santa Rosa, California: Post Carbon Institute.

[18]. Inhorn. M.C., Thomsen. T.-T., Goldberg, H and Mosegaard, C. (2009) Reconceiving the Second Sex: Men, Masculinity and Reproduction. New York: Berghahn Books.

[19]. Iribhoghe, O.O., Akpamu, U., Nwaopara, A.O., Osifo, C.U and Otamare, H.O. (2012) Contraceptive Choice among Men in Ekpoma, Nigeria. African Journal of Biomedical Research. Pages 8.

[20]. Jones, M. M. (2012) Human Reproductive Biology. San Diego, California: Academic Press.

[21]. Jones, T.(2010) Comprehensive Medical Terminology. New York: Cengage Learning.

[22]. Jensen, S. M. (2010) Encyclopedia of Contemporary American Social Issues. Santa Barbara: ABC-CLIO.

[23]. Kibagenyi, A., Ndugga, P., Wandera, S.O and Kwagala, B. (2014) "Modern contraceptive use among sexually active men in Uganda: does discussion with a health worker matter." BioMed Central - Public Health: Page 8.

[24]. Khurram, A.S and Graham, B (2008) Barriers and Perceptions of Opinion Leades Regarding the Use of Modern Contraception Methods in Slum Areas of Karachi, Pakistan: A Qualitative Study. Perth: Curtin University of Technology. Pg 43.

[25]. Khana. O. P and Jain T.R (2007) Development Problems and Policies. Delhi: Vimla Kumari Publications.

[26]. KNBS (2014) Kenya Demographic and Health Survey: Key Indicators. Nairobi: Government Printers

[27]. KNBS (2010): Kenya Demographic and Health Survey (2008-09). Nairobi: Government Printers.

[27a]. MoFP (2009) Kisii Central District Development Plan (2002 - 2008) Nairobi: Government Printers.

[27b]. MoFP (2009) Nakuru District Development Plan (2002 - 2008) Nairobi: Government Printers.

[28]. Ladipo, L., Ademola A and Philomena O (2013) International Conference on Family Planning Addis Ababa, Ethiopia. 28 April 2015.

[29]. Lancet. (2012) Lancet: Family Planning: Global Health Series. New York: Elsevier Health Science.

[30]. Liebert, M. A. (2008) AIDS Patient Care and STDs. North Hollywood: Mary Ann Liebert, Inc. Publishers.

[31]. Manuh, T and Addy, E.S. (2014) Africa in Contemporary Perspective: A Textbook for Undergraduate Students. Accra: Sub - Saharan Publishers.

[32]. May, W. E. (2009): Marriage: The Rock on which the Family is Built. San Francisco: Ignatius Press.

[33]. Mazur, L. A. (2013) Beyond the Numbers: A Reader on Population, Consumption and the Environment. Washington: Island Press.

[34]. MedicineNet. (2012) Definition of Birth Control. Retrieved from MedicineNet.com: www.medicinenet.com/script/main/mobileart.asp?articlekey=53351 Accessed on 27 March, 2015.

[35]. Morna Collen Lowe, Dube Sifiso, Makamure Lucia and Cathrine N robinson (2014) The SADC Protocol on gender and development. Southern Africa gender protocol alliance. Johannesburg, South Africa.

[36]. Mundo, F. D. (2012) Primary Maternal and Neonatal Health: A Global Concern. Chicago: Springer Science $\&$ Media Centre.

[37]. Nasir, J. T. (2010) Contraceptive Attitude and Behaviuor among University Men: A Study From Punjab, Pakistan. J AyubMed Coll Abbottabad, pg 1-4.

[38]. Nieschlag, E., Behre, H. M and Nieschlag, S.(2010) Andrology: Male Reproductive Health and Dysfuction. Munster: Springer Science \& Business Media.

[39]. Oxford English Dictionary (2012) Oxford: Oxford University Press.

[40]. Osei, I. M. (2014) Fertility Decisions and Contraceptive Use at Different Stages of Relationships: Windows of Risk among Men and Women in Accra. International Perspectives on Sexual and Reproductive Health, pg 3240.

[41]. Ochako, R., Mbondo, M., Aloo, S., Kaimenyi, S., Thompson, R., Temmerman, M and Megan K (2015) Barriers to modern contaceptive methods uptake among young women in Kenya: A qualitative study. BioMed Central: Public Health. Pg 11.

[42]. Steinfeld, R.L., Newmann, S.J., Onono M., Cohen, C.R., Bukusi, E.A and Grossman, D. (2013) Overcoming Barriers to Family Planning through Integration: Perspectives of HIV-Positive Men in Nyanza Province, Kenya. Nairobi: Hindawi Journals. Pg 8.

[43]. Tsehaye, W.T., Mengistu, D., Birhanu, E and Berhe, K.K. (2013) "Assessment of Preference and its Determinant Factors to Ward Modern Contraceptive Methods among Women of Reproductive Age Group in Shire Indaselassie Town, Northern Ethiopia, 2011." International Journal of Family Medicine: page 8. 
South American Journal of Public Health

Volume 4, Issue 1, 2016

[44]. Tountas, Y., Creatsas, G and Dimitrakaki, C. (2004) Information sources and level of knowledge of contraception issues among Greek women and men in the reproductive age: a country-wide survey. Eur $J$ Contracept Reprod Health Care: Pg10.

[45]. WHO. (2013) Task Shifting to Improve Access to Contraceptive Methods. Sexual and Reproductive Health, 4. Retrieved from WHO.

[46]. WHO. (2015) Health Topics. Family Planning. http://www.who.int/mediacentre/factsheets/fs351/en/ Accessed on 27 March 2015.

[47]. Weigl, C. (2010) Reproductive Health Behaviour and Decision-making of Muslim Women. Munster: LIT Verlag.

[48]. World Bank (2010) Available from http://data.worldbank.org/indicator/SP.DYN.TFRT.IN, data assessed $24^{\text {th }}$ September, 2015. 